\title{
Desempenho do Reator de Fluxo Ascendente com Leito de Lodo (UASB) na Redução do Poder Poluente de Águas Residuárias de Suinocultura
}

\section{FERNANDA L. A. FERREIRA ${ }^{1}$, LUIZ A. DO AMARAL ${ }^{1}$ E JORGE DE LUCAS JR. ${ }^{2}$}

${ }^{1}$ Departamento de Medicina Veterinária Preventiva e ${ }^{2}$ Departamento de Engenharia Rural, Faculdade de Ciências Agrárias e Veterinárias, UNESP, Câmpus de Jaboticabal, Via de Acesso Prof. Dr. Paulo Donato Castellane, Km 5, 14884.900, Jaboticabal, SP.

\section{RESUMO}

Os resíduos produzidos na suinocultura, ricos em matéria orgânica e patógenos, são freqüentemente responsáveis pela poluição do solo, ar e água. A utilização da biodigestão anaeróbia é uma alternativa viável encontrada para redução do poder poluente de águas residuárias de suinocultura. No presente estudo, avaliou-se o desempenho do reator de fluxo ascendente com leito de lodo (UASB). Observou-se que os valores médios da demanda química de oxigênio (DQO), de fósforo $(\mathrm{P})$, nitrogênio $(\mathrm{N})$, zinco $(\mathrm{Zn})$ e cobre $(\mathrm{Cu})$ sofreram variações decrescentes a partir da entrada no biodigestor, reduzindo o impacto ambiental que causariam, porém não houve redução significativa das concentrações de sódio $(\mathrm{Na})$ ao longo do sistema. A produção de biogás demonstrou a eficiência do sistema do ponto de vista energético.

Os estudos realizados demonstraram a possibilidade de redução drástica do poder poluente de águas residuárias de suinocultura.

PALAVRAS-CHAVE: dejetos de suínos; biodigestão anaeróbia; impacto ambiental; metais pesados; biogás.

\section{ABSTRACT}

The residues produced on swine breeding farms, rich in organic matter and 
pathogens, are frequently responsible for the pollution of the soil, air and water. Among the alternatives found to solve the environmental impact caused by the large amount of residues produced on a pig breeding farms, the upflow anaerobic sludge blanket (UASB) reactor can be used as an alternative for the treatment of wastewaters with low solid content, to reduce the polluting power of the residues to a minimum. There is a concomitant production of biogas as subproducts of the process, which can be used for practical applications on rural properties. It was determined the concentrations of chemical oxygen demand (COD), phosphorus $(\mathrm{P})$, nitrogen $(\mathrm{N})$, zinc $(\mathrm{Zn})$, copper $(\mathrm{Cu})$ and sodium $(\mathrm{Na})$ in swine wastewaters along treatment in UASB reactor. The biogas production was calculated to evaluate the energetic potential of swine wastewaters.

The results shown that anaerobic technology with UASB reactor can feasible in the treatment of swine wastewater, reducing the volume and the polluting power of the residues to a minimum.

Key-words: swine wastewaters; UASB reactor; environmental impact; heavy metals; biogas.

\section{INTRODUÇÃO}

O aumento da produção de alimentos, principalmente os de origem animal, decorrente do crescimento da população mundial, agravou de modo sensível a geração de resíduos. A mudança das características dos sistemas de produção, de uma tradicional agricultura familiar para um sistema tecnificado com capacidade de gerar grande quantidade de proteína animal em reduzido espaço físico, comprometeu irreversivelmente a qualidade do solo, ar e água como resultado do manejo e disposição incorreta de resíduos provenientes das atividades agrícolas.

No Brasil, o oeste do Estado de Santa Catarina, região que se destaca pela grande concentração de produtores e indústrias de processamento de carne suína, enfrenta sérios problemas de contaminação de mananciais, decorrentes do manejo inadequado das águas residuárias da suinocultura (OLIVEIRA, 1993; GARCIA \& BEIRITH, 1996).

Em 1995, no Canadá, o derramamento de aproximadamente 7,6 milhões de litros de águas residuárias da suinocultura e 32,6 milhões da avicultura em uma fonte de água provocou a morte de milhões de peixes e a contaminação de vários rios com uma elevada concentração de coliformes fecais (MALLIN et al., 1997). No ano seguinte, 40 transbordamentos de lagoas de armazenamento de águas residuárias foram responsáveis pela morte de aproximadamente 700.000 peixes em Iowa, Minesota e Missouri, nos Estados Unidos.

Entre os elementos presentes nos dejetos, envolvidos na degradação do meio 
ambiente, destacam-se o fósforo $(\mathrm{P})$, nitrogênio $(\mathrm{N})$, zinco $(\mathrm{Zn})$ e cobre $(\mathrm{Cu})$.

O fósforo, quando aplicado várias vezes e em doses acentuadas, pode ser transportado pela água de escoamento superficial de chuvas, provocando a eutrofização dos ecossistemas aquáticos receptores, inviabilizando a sobrevivência da flora e fauna (SHARPLEY \& WITHERS, 1994). O nitrogênio, além de também estar envolvido no processo de eutrofização, representa um sério problema de saúde pública e animal quando é convertido a nitrato, que está associado à ocorrência da metaemoglobinemia e a formação potencial de nitrosaminas e nitrosamidas carcinogênicas (MATO, 1996; AWWA, 1990).

O cobre e o zinco estão presentes em altas concentrações nos dejetos de suínos (NICHOLSON et al., 1999) porque eles são amplamente utilizados na formulação de antibióticos, como suplementos dietéticos e promotores de CRESCIMENTO (PATTERSON, 1984; CHOI, 1985). Quando absorvido pelas plantas, podem provocar problemas de fitotoxicidade, e quando não, podem percolar ou ser transportados pela água da chuva, causando dessa forma, a contaminação de fontes de água subterrâneas e superficiais. Quando entram na cadeia alimentar humana, acumulam-se no organismo, provocando sérias enfermidades.

Além do processo de eutrofização e contaminação ambiental por metais pesados, pode-se destacar o risco potencial de salinização do solo. A aplicação descontrolada de resíduos no solo, além das necessidades das culturas, provoca o aumento do teor de sais, já que as fezes e urina são ricas em sódio e potássio. (WESTERMAN et al., 1987).

A biodigestão anaeróbia pode ser utilizada como alternativa no tratamento de resíduos sólidos e líquidos, para redução do poder poluente e dos riscos sanitários dos dejetos ao mínimo, tendo, ao mesmo tempo, como subproduto desse processo, o biogás e o biofertilizante, com várias aplicações práticas na propriedade rural. Ademais, existem diversos modelos de biodigestores disponíveis, cada um se adequando a um tipo de resíduo, em relação à sua diluição (LUCAS JR., 1994).

Os biodigestores de fluxo ascendente (UASB) estão adaptados para águas residuárias com baixo teor de sólidos, o que motiva a sua utilização no tratamento de águas residuárias das atividades de suinocultura, pois o dejeto de suínos se apresenta muito diluído em águas de lavagem, de bebida desperdiçada e na própria urina.

Diante do exposto, o objetivo deste estudo foi avaliar o desempenho do biodigestor de fluxo ascendente com leito de lodo (UASB) como alternativas para o tratamento mais eficiente de águas residuárias de suinocultura. 


\section{MATERIAL E MÉTODOS}

Caracterização do sistema de tratamento. $\mathrm{O}$ experimento foi desenvolvido em sistema de tratamento de águas residuárias instalado em área experimental do Departamento de Engenharia Rural da Faculdade de Ciências Agrárias e Veterinárias, UNESP, Câmpus de Jaboticabal. O sistema é composto por caixa de entrada, destinada ao preparo do substrato (dejeto e água); caixas de armazenamento, permitindo a alimentação contínua do sistema; decantador, destinado à remoção de sólidos sedimentáveis; caixa reguladora de vazão, destinada a alimentar o sistema de acordo com o tempo de retenção hidráulica (TRH) estabelecido; e dois biodigestores de fluxo ascendente com leito de lodo (UASB), baseados em modelo proposto por LETTINGA et al. (1980), cada um com volume útil de substrato igual a 705L.

Os reatores UASB foram operados com água residuária de pocilgas prédecantada com teor de sólidos totais de $2474 \mathrm{mg} \mathrm{L}^{-1}$ e tempo de retenção hidráulica (TRH) de 14 horas em cada reator.

Amostragem. Amostras de água residuária foram colhidas semanalmente para realização das análises físico-químicas, com cinco repetições de cada análise. Os pontos de colheita, identificados com as letras A, B, C e D, conforme Figura 1, equivalem respectivamente à caixa de carga, caixa reguladora de vazão, primeiro e segundo biodigestor de fluxo ascendente (UASB).

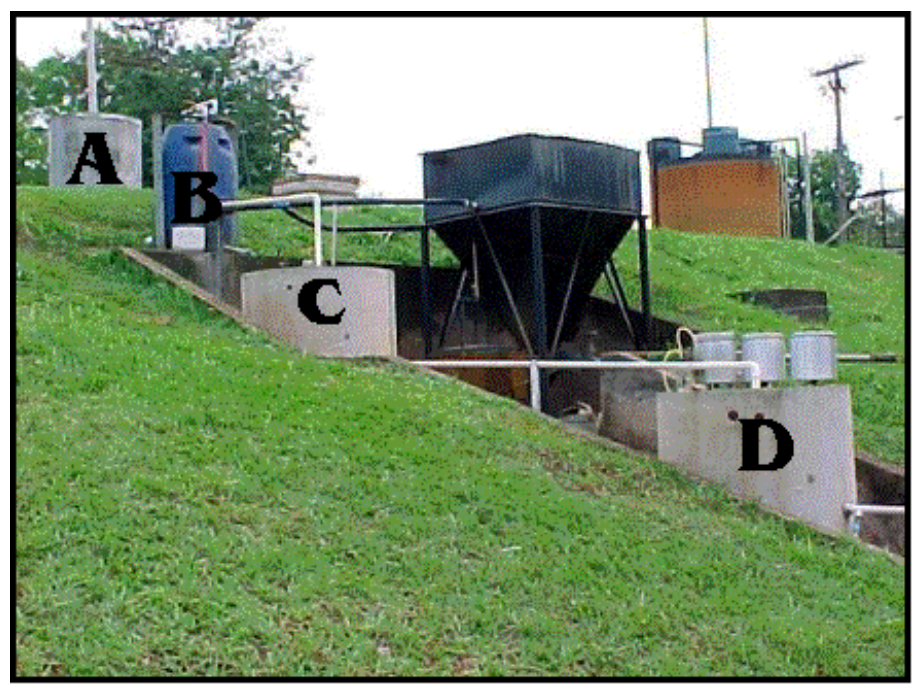

Figura 1: Visualização do sistema de tratamento e identificação dos pontos de colheita de amostras: caixa de carga (A), caixa reguladora de vazão $(B), 1^{\circ}$ e $2^{\circ}$ reator de fluxo ascendente (C e D).

Metodologia analítica. Para determinar a Demanda Química de Oxigênio (DQO), as amostras foram submetidas à digestão ácida em meio contendo dicromato de 
potássio e catalizadores. Posteriormente, os valores foram obtidos por método colorimétrico em espectrofotômetro modelo DR-2000 (APHA, 1992).

$\mathrm{O}$ fósforo $(\mathrm{P})$ foi determinado por método colorimétrico, empregando metavanadato e molibidato de amônio e o nitrogênio total $(\mathrm{N})$ pelo método Semi-Micro Kjedahl que tem como princípio, a transformação do Nitrogênio amoniacal em amônia $\left(\mathrm{NH}_{3}\right)$ que é fixada pelo ácido bórico e posteriormente titulada com ácido sulfúrico $\left(\mathrm{H}_{2} \mathrm{SO}_{4}\right)$. Ambas as metodologias equivalem àquelas descritas no APHA (1992). As concentrações de cobre $(\mathrm{Cu})$, zinco $(\mathrm{Zn})$ e sódio $(\mathrm{Na})$ foram determinadas através da digestão nítrico-perclórica para obtenção do extrato e posterior leitura em espectrofotômetro de absorção atômica.

Os volumes de biogás produzidos diariamente foram determinados medindose o deslocamento vertical dos gasômetros e multiplicando-se pela área de sua seção transversal interna, que é igual a $0,3421 \mathrm{~m}^{2}$ para o primeiro reator de fluxo ascendente e $0,0369 \mathrm{~m}^{2}$ para o segundo. A correção do volume do biogás para as condições de $1 \mathrm{~atm}$ e $20^{0} \mathrm{C}$ foi efetuada com base no trabalho de CAETANO (1985).

\section{RESULTADOS E DISCUSSÃO}

\section{Demanda Química de Oxigênio (DQO), Nitrogênio total (N) e Fósforo (P).}

As concentrações médias de DQO, $\mathrm{N}$ e $\mathrm{P}$ nos afluentes e efluentes do sistema de tratamento, em cada ponto de colheita, são apresentadas na Tabela 1.

Tabela 1: Concentrações médias de DQO, Nitrogênio total (N) e Fósforo (P), em miligramas por litro $\left(\mathrm{mg} \mathrm{L}^{-1}\right)$, em cada ponto de colheita do sistema.

\begin{tabular}{||c||c||c||c||}
\hline \multirow{2}{*}{$\begin{array}{c}\text { Ponto de } \\
\text { Colheita }\end{array}$} & DQO & N & P \\
\cline { 2 - 4 } & $----------\mathrm{mg} \mathrm{L}^{-1}$ & \\
\hline \hline A & 5.062 & 23 & 274 \\
\hline \hline B & 1.703 & 19 & 209 \\
\hline \hline & & & \\
\hline
\end{tabular}




\begin{tabular}{||l||l||l||l||}
$\mathrm{C}$ & 968 & 17 & 196 \\
\hline \hline $\mathrm{D}$ & 588 & 16 & 183 \\
\hline
\end{tabular}

Os valores médios da DQO foram diminuindo, à medida que as águas residuárias foram percorrendo o sistema, alcançando, ao final do tratamento, uma redução de $88,4 \%$, resultado bastante promissor se comparado aos obtidos por Souza \& Vieira (1986), que avaliaram a eficiência de um reator UASB com quatro horas de tempo de retenção hidráulica (TRH), tratando esgoto doméstico pré-decantado, referindo uma eficiência de 62,0\% de remoção de DQO, à temperatura ambiente.

Da mesma forma, as concentrações médias de fósforo e nitrogênio total diminuíram, atingindo o maior percentual de redução, 18,0\% para o fósforo e 24,0\% para o nitrogênio total, após o tratamento físico no decantador, destinado à remoção de sólidos sedimentáveis, que equivale ao ponto B de colheita de amostras. Apesar da redução total de $29,3 \%$ para o fósforo e $33,2 \%$ para o nitrogênio, os efluentes, ao final do processo, estão em desacordo com os padrões estabelecidos pelo Conselho Nacional do Meio Ambiente (CONAMA, 1986) para águas destinadas à irrigação de culturas vegetais de qualquer tipo.

Zinco (Zn), Cobre (Cu) e Sódio (Na). As concentrações médias de $\mathrm{Zn}, \mathrm{Cu}$ e $\mathrm{Na}$ nos afluentes e efluentes do sistema de tratamento, em cada ponto de colheita, são apresentadas na Tabela 2.

Tabela 2: Concentrações médias de Zinco $(\mathrm{Zn})$, Cobre $(\mathrm{Cu})$ e Sódio $(\mathrm{Na})$, em miligramas por litro $\left(\mathrm{mg} \mathrm{L}^{-1}\right)$, em cada ponto de colheita do sistema.

\begin{tabular}{|c|c|c|c|}
\hline \multirow{2}{*}{$\begin{array}{l}\text { Ponto de } \\
\text { Colheita }\end{array}$} & $\mathrm{Zn}$ & $\mathrm{Cu}$ & $\mathrm{Na}$ \\
\hline & \multicolumn{3}{|c|}{--------- $\mathrm{mg} \mathrm{L}^{-1}$} \\
\hline A & 3,7 & 4,9 & 5,1 \\
\hline B & 2,3 & 2,9 & 5,4 \\
\hline $\mathrm{C}$ & 0,9 & 1,5 & 5,1 \\
\hline
\end{tabular}




\begin{tabular}{|l||l||l||l||}
$\mathrm{D}$ & 0,4 & 0,6 & 4,4 \\
\hline
\end{tabular}

No geral, houve redução dos teores de zinco e cobre ao longo do sistema de tratamento, atingindo ao final do processo, percentuais de redução de respectivamente 90,0 e 87,8\%, possivelmente devido à complexação pela matéria orgânica e retenção nos biodigestores de fluxo ascendente. Deve-se destacar que o lodo, nos reatores UASB, tem volume menor que os efluentes e pode, em situações específicas e controladas, ser lançado no solo sem prejuízo ao ambiente. Os efluentes, de acordo com os padrões estabelecidos pelo Conselho Nacional do Meio Ambiente (CONAMA, 1986), de $0,5 \mathrm{mg} \mathrm{L}^{-1}$ para o cobre e $5 \mathrm{mg} \mathrm{L}^{-1}$ para o zinco, poderão ser utilizados na irrigação de culturas arbóreas, cerealíferas e forrageiras.

Observa-se que não houve redução expressiva dos teores médios de sódio. Conclui-se que, enquanto o cobre e o zinco ficaram retidos no biodigestor na forma de precipitados insolúveis, o sódio permaneceu na fração líquida das águas residuárias de suinocultura (STANOGIAS \& PEARCE, 1987).

Alguns autores destacam a possibilidade do sódio interferir na eficiência do processo de biodigestão anaeróbia e conseqüente produção de biogás em um reator de fluxo ascendente com leito de lodo (UASB). Porém, os teores de sódio determinados nos efluentes do sistema e durante todo o processo de tratamento mantiveram-se bastante abaixo dos $7.000 \mathrm{mg} \mathrm{L}^{-1}$, a partir do qual poderia ser constatada inibição acima de $86,0 \%$ da disgestão anaeróbia (HANSEN et al., 1989; RINZEMA et al., 1988).

Produção de Biogás. O poder energético das águas residuárias de suinocultura também deve ser considerado, pois $1 \mathrm{~m}^{3}$ de biogás é equivalente energético a 0,66 litros de diesel ou 0,7 litros de gasolina (OLIVEIRA, 1993).

As produções médias de biogás no primeiro e segundo reator de fluxo ascendente são apresentadas na Tabela 3.

Tabela 3: Valores médios de produção de biogás nos biodigestores 1 e 2., em litros por hora $\left(\mathrm{L} \mathrm{h}^{-1}\right)$ e em metros cúbicos de biogás por metro cúbico de biodigestor, por dia $\left(\mathrm{m}^{3}\right.$ $\left.\mathrm{m}^{-3} \mathrm{dia}\right)$.

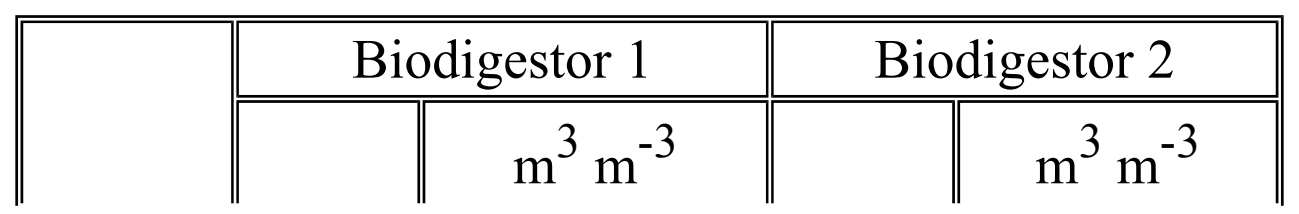




\begin{tabular}{|c||c||c||c||c||}
\multicolumn{1}{|c||}{ Semanas } & \multicolumn{1}{|c||}{$\mathrm{L} \mathrm{h}^{-1}$} & $\begin{array}{c}\text { biodigestor } \\
\text { dia }\end{array}$ & $\mathrm{L} \mathrm{h}^{-1}$ & $\begin{array}{c}\text { biodigestor } \\
\text { dia }\end{array}$ \\
\hline \hline 1 & 4,983 & 0,170 & 0,690 & 0,024 \\
\hline \hline 2 & 9,857 & 0,336 & 0,882 & 0,030 \\
\hline \hline 3 & 7,866 & 0,268 & 2,015 & 0,069 \\
\hline \hline 4 & 7,715 & 0,263 & 0,940 & 0,032 \\
\hline \hline 5 & 7,799 & 0,265 & 0,621 & 0,021 \\
\hline \hline 6 & 7,000 & 0,238 & 0,482 & 0,016 \\
\hline \hline 7 & 5,591 & 0,190 & 0,903 & 0,031 \\
\hline \hline 8 & 5,201 & 0,177 & 0,832 & 0,028 \\
\hline \hline 9 & 5,676 & 0,193 & 3,191 & 0,109 \\
\hline \hline 10 & 3,875 & 0,132 & 1,531 & 0,052 \\
\hline \hline 11 & 4,120 & 0,140 & 1,749 & 0,060 \\
\hline \hline 12 & 4,161 & 0,142 & 1,180 & 0,040 \\
\hline \hline 13 & 4,618 & 0,157 & 1,330 & 0,045 \\
\hline \hline Média & 6,036 & 0,205 & 1,257 & 0,043 \\
\hline \hline
\end{tabular}

Observa-se que a produção média de biogás no primeiro biodigestor foi superior à do segundo durante todo o período devido possivelmente a maior concentração de ácidos orgânicos nos afluentes do primeiro reator, mantendo o mesmo comportamento de estudos anteriores (IAMAMOTO et al., 2000; LUCAS JR., 1994).

\section{CONCLUSÕES}

Os resultados mostraram que o biodigestor de fluxo ascendente com leito de lodo (UASB) é uma alternativa viável no tratamento de águas residuárias de suinocultura, reduzindo o poder poluente dos resíduos e evitando a poluição dos recursos naturais causada pela sua emissão descontrolada. Ademais, produziu o biofertilizante com baixas concentrações de zinco e cobre.

\section{AGRADECIMENTOS}

Os autores agradecem à FAPESP (Fundação de Amparo à Pesquisa do Estado de São Paulo) pelo apoio financeiro. 


\section{REFERÊNCIAS BIBLIOGRÁFICAS}

AMERICAN PUBLIC HEALTH ASSOCIATION (APHA). Standard methods for the examination of water and wastewater. $17^{\mathrm{a}} \mathrm{ed}$. Washington, 1992.

AMERICAN WATER WORKS ASSOCIATION (AWWA). Water quality and treatment: a handbook of community water supplies. $4^{\text {a }}$ ed. New York: McGrawHill, 1990.

CAETANO, L. Proposição de um sistema modificado para quantificação de biogás. 1985. 75f. Dissertação (Mestrado em Energia na Agricultura) - Faculdade de Ciências Agronômicas, Universidade Estadual Paulista, Botucatu, 1985.

Choi, J.H. Growth promoting effect of Zn-bacitracin on growing-finishing swine. Nutrition Reports International., v.32, n.6, p. 1421-1424, 1985.

CONSELHO NACIONAL DO MEIO AMBIENTE (CONAMA). Padrões de Qualidade para os Parâmetros Monitorados na Rede de Monitoramento, segundo Resolução CONAMA 20/86, 1986.2 Disponível em: http://www.cetesb.sp.gov.br/QualidadeRios/anexo2. Acesso em: 22 jul. 2000.

GARCIA, T.; BEIRITH, B. Quantificação da contaminação dos rios pela biomassa da suinocultura em Santa Catarina (região oeste): estudo e comparação da poluição dos mananciais de abastecimento públicos. 1996. 49f. Monografia. Universidade do oeste de Santa Catarina, Chapecó, 1996.

HANSEN, C. L.; BIAN, Y.; CHOUDHURY, G. S. Anaerobic digestion of whey permeate in an upflow anaerobic sludge blanket digester. Journal of Dairy Science, v. 72, suppl.1, p.134-135, 1989.

IAMAMOTO, C. Y.; OLIVEIRA, R. A.; LUCAS Jr. Effect of organic loading rate combination in series of upflow anaerobic sludge blanket (UASB) reactors in the swine wastewater treatment. In: OFICINA E SEMINÁRIO DE DIGESTÃO ANAERÓBIA, 6., 2000, Recife. Anais...Recife: Editora Universitária da UFPE, 2000. p.37-40.

LETTINGA , G.; VANVELSEN, A. F. M.; HOBMA, S. W.; DEZEEUW, W.; KLAPWIJK, A. Use of upflow sludge blanket (UASB) reactor concept for biological wastewater treatment, especially for anaerobic treatment. Biotechnology Bioengineering, New York, v.22, p. 699-734, 1980.

LUCAS Jr., J. Algumas considerações sobre o uso do estrume de suínos como 
substrato para sistemas de biodigestores anaeróbios. 1994. 137p. Tese (LivreDocência) - Faculdade de Ciências Agrárias e Veterinárias, Universidade Estadual Paulista, Jaboticabal, 1994.

MALLIN, M. A.; BURKHOLDER, J. M.; McIVER, M. R.; SHANKS, G. C.; GLASGOW, H. B.; TOUCHETE, B. W.; SPRINGER, J. Comparative effects of poultry and swine waste lagoon spills on the quality of receiving streamwaters. Journal of Environmental Quality, v.26, p.1622-1631, 1997.

MATO, A. P. Determinação de nitratos, nitritos e prováveis fontes de contaminação em águas de poços e sua influência na metemoglobinemia infantil. 1996. Dissertação (Mestrado) - Universidade Mackenzie, São Paulo, 1996.

Nicholson, F. A.; Chambers, B. J.; Williams. j. r.; Unwin, r. j. Heavy metal contents of livestock feeds and animal manures in England and Wales. Bioresourse Technology, v. 70, p.23-31, 1999.

OLIVEIRA, P. A. V. Manual de manejo e utilização dos dejetos de suínos. Concórdia: Empresa Brasileira de Pesquisa Agropecuária (EMBRAPA-CNPSA), 1993. 188p. (Documentos, 27).

Patterson, D.C. Effects of dietary inclusion of copper sulphate, avopacin and carbadox/sulphadimine supplements on the performance of pigs weaned at 25 days. Animal Production, v.38, n.3, p.487-493, 1984.

RINZEMA, A., LIER, V. VAN; LETTINGA, G. Sodium inhibition of acetoclastic methanogens in granular sludge from a UASB reactor. Enzyme \& Microbial Ecology, v.10, n.1, p.24-32, 1988.

SHARPLEY, A. N. ; WITHERS, P. J. A. The environmentally-sound management of agricultural phosphorus. Fertilizer Research, v.39, n.2, p. 133-146, 1994.

SOUZA, M. E.; VIEIRA, S. M. M. Uso do reator UASB para tratamento de esgoto sanitário. Revista DAE, v.46, n.145, p. 165-168, 1986.

STANOGIAS, G. B.; PEARCE, G. R. The effect of high concentrations of minerals in pig diets on the convertibility to metane and in vitro digestibility of resulting pig faeces. Biological Wastes, v.21, n.12, p.111-132, 1987.

WESTERMAN, P. W.; KING, L. D.; BURNS, J. C.; CUMMINGS, G. A.; OVERCASH, $M$. R. Swine manure and lagoon efluent applied to a temperate forage mixture II - Rainfall runoff and soil chemical properties. Journal of Environmental Quality, v.16, n.2, p.106-112, 1987. 